\title{
Managerial Skills in Technical Professionals - An Exploration of IT Project Leadership
}

\author{
M.R.Thite \\ Swinburne University of Technology \\ PO Box 218, Hawthorn, VIC 3122, Australia \\ Tel./Fax: 61-3-98185765 \\ Email: Mthite@swin.edu.au
}

\begin{abstract}
This paper focuses on the nature, characteristics and styles of technical project leadership. The literature survey highlights and analyses the poor performance of technical professionals in managerial roles and discusses successful technical leadership styles. Transformational leadership model is sought to be tested in an Australian IT project environment along with other critical success factors. The methodology and the instruments used in the research in progress are discussed.
\end{abstract}

\section{Keywords}

Technical project leadership, transformational leadership, project management, information technology projects.

\section{INTRODUCTION}

Organisations are undergoing a paradigm shift under the shock of technological revolution. The impact of this revolution is evidenced by the rapidly changing distribution of work force. The technicians are becoming the core employees of the digital information age. The sheer growth in the number of technicians and the diversity of occupations they hold bespeak a 
profound change in the importance to companies that hope to survive and thrive in an era of epochal change (Richman, 1994).

Compared to other occupational groups, the management and leadership of technical employees pose unique challenges. Some of the distinguished characteristics associated with technical professionals are: desire for autonomy, sense of achievement, fear of burnout, first loyalty to profession and second to employment, resistance to mandated organisational goals etc. (Rosenbaum, 1991). Scientific and professional employees perform work that is intellectual in nature and requires advanced education. They need to be self-disciplined and achievement - oriented. They prefer considerable autonomy and tend to be cosmopolitans more than locals (Davis, 1981:281).

\section{TECHNICAL PROFESSIONALS IN MANAGEMENT}

While analysing the role of scientific/technical professionals in management, Davis (1981:278) suggests that they are a major source of talent for promotion to management, but sometimes, their transition to management is difficult, particularly if they lack management and behavioural training. Their orientation towards logic, the physical world and / or the frame work of their specialty may result in narrow view points and blind spots.

The challenge is even greater for most technical leaders, who often come to management positions because of their technical competence, not their interpersonal abilities. Many such leaders assume their responsibilities without adequate role models. In general, technical leaders who come from technological backgrounds have abilities, personalities, and interests that are oriented more toward things than people. They can manage the technical aspects of the job, but are not adept at managing the people involved in it. But the fast paced, competitive world of technology requires balanced leaders who are responsive to the needs of technical professionals and to the organisation's strategic objectives (Rosenbaum, 1991).

A number of organisations have attempted to create alternate career paths for technical people who do not wish to become managers but they have invariably failed (Power, 1995). Today one needs to be a "hybrid" manager with both technical and managerial credentials.

\section{FOCUS ON TECHNICAL LEADERSHIP}

This paper highlights one of the most important managerial skills required in technical professionals- Leadership. The nature, characteristics and styles of technical leadership are undergoing fundamental changes. Today, the focus is on virtual (Huey, 1994:42), post-heroic (Bradford and Cohen, 1984), or transformational leadership (Bass, 1985; Tichy \& Devanna, 1986). Since technical professionals are highly specialised, managing them according to traditional principles may meet with only minimal success. While superior technical ability can influence short-term managerial success, interpersonal effectiveness is necessary for a technical leader's long-term achievement (Rosenbaum, 1991). 
To successfully manage today's all-important technical employees, organisations require powerfully effective leaders who understand the unique needs and aspirations of their technical subordinates and lead them accordingly. Successful projects almost always have a "champion" who either by past experience or by persistent determination provides needed leadership to members of the project team to see that results are achieved (Cash \& Fox, 1992).

An analysis of the literature and empirical research shows that there is a widespread view that technical professionals lack leadership skills. In its report "Promoting Partnerships" (Schapper et all, 1992), the Schapper Task Force made a critical claim that Australia is deficient in number and quality of technical project leaders. This claim was examined in detail by a Task Force on Leadership (Mann et all, 1994) which found widespread agreement that industrial R\&D in Australia is hampered by the quality of R\&D project leaders. The report added that the same was the case in the U.S.

\section{LITERATURE REVIEW ON TECHNICAL LEADERSHIP}

The literature on organisation, technology and people has occasionally dealt with the special and specific characteristics of technical professionals, their importance in today's increasingly technology - oriented organisations, how their motivational needs are different and therefore, how Human Resource Management policies and leadership skills required to manage them need to be looked at from a different perspective. However, some studies have specifically focused their attention on technical leadership and have suggested the best-possible leadership style to successfully manage technical professionals.

\section{Heroic and Post-heroic Leadership Styles}

Bradford and Cohen (1984) analysed heroic - styles of leadership (manager - as - master technician and manager - as - conductor) and concluded that while they had their own strengths, they are not suitable to foster excellence in organisations characterised by complex tasks, highly interdependent subordinates' work, a constantly changing environment and competent subordinates.

The manager - as - master - technician may be a technical wizard but his style characterised by technical rather than managerial aspects of the job undermines subordinates' confidence, stifles their growth, ignores organisational systems and procedures, and over emphasises technical problems to the detriment of people problems. The manager - as - conductor encourages group decision making process and respects organisational systems and procedures but fails to balance diverse specialised concerns and view points leading to suppression of subordinate development and causing increased manipulation and strategic manoeuvring. Thus, both Technical and Conductor models are likely to prevent excellence, overuse task - abilities of the leader and under-utilise the competencies of subordinates (p. 3357).

A post - heroic leader model (Manager - as - developer) is then presented by Bradford and Cohen. The essential components of this model are: building a shared responsibility team, continuous development of individual's skills and determining and building a common 
department vision. The benefits of this leadership style are: increased chance of accomplishing tasks at a higher level of quality; extension of subordinate's feeling of responsibility beyond task issues to managerial issues; and increased subordinate motivation. The manager - as developer has in his/her mind developmental, collaborative, galvanising, but subordinate centred image (p. 60-61).

\section{Problem-solving Leadership Style}

Weinberg (1986), an acknowledged expert on technical leadership, compared successful and unsuccessful introduction of new technical systems and concluded that "almost all of the successes hinged on the performance of a small number of outstanding technical workers. What distinguished them from their less successful colleagues was a rare combination of technical expertise, and leadership skills. These people had transformed themselves from ordinary technical supervisors into problem solving leaders, with the power to make things happen." (p. viii).

While analysing the leadership styles of technical leaders, Weinberg observed that "if we look more closely at how technical leaders emphasise on innovation, we find that they concentrate on three major areas: understanding the problem, managing the flow of ideas, and maintaining quality. These functions are the ingredients that characterise the problem-solving leadership style. This is the style that characterises the best technical leaders." (p. 21)

\section{High-touch Leadership Style}

Rosenbaum (1991), and his team conducted extensive research over a three year period on the leadership of technical professionals in nineteen technology- oriented companies. They found many common patterns related to effective technical leadership. Successful leaders :

- Coach for peak performance by aligning individual and organisational goals; making performance analyses; and managing change.

- Run organisational interference by teaching subordinates how to take advantage of organisational opportunities and remove organisational obstructions from the path to innovation.

- Orchestrate the professional development of their subordinates, by providing the business perspective; building and encouraging champions; and facilitating career development.

- Expand individual productivity through team work by establishing clear goals; clarifying roles; securing resources; and implementing information exchange systems.

- Facilitate self management by sharing information; delegating responsibility; and encouraging upward communication.

The study concluded that technical leaders in a high-technology world need to be "Hightouch", that is, adept at communicating, influencing and motivating. 


\section{Transformational Leadership Style}

Transformational leadership, transactional leadership, and non-leadership, form a new paradigm for understanding both the lower- and higher-order effects of leadership (Bass and Avolio, 1989:1). Bass (1985) described transformational leaders as those who:

- Raise followers' level of awareness of the importance of achieving valued outcomes and the strategies for reaching them.

- Encourage followers to transcend their own self-interest for the sake of the team, organisation, or larger policy.

- Develop followers' needs to higher levels in such areas as achievement, autonomy, and affiliation, which can be both work-related and non work-related.

The relevance of the model in the technical/scientific fields has been empirically tested by several studies as follows:

A longitudinal study of transformational leadership and the performance of project groups in three R\&D organisations found that transformational leadership predicted higher project quality and budget/schedule performance ratings (Keller, 1992).

Howell and Higgins (1990) examined the personality characteristics, leadership behaviours and influence tactics of champions of technological innovation in Canada. Analyses of matched pairs of champions and non-champions showed that champions reported using transformational leader behaviours to a significantly greater extent than did non-champions. Champions exhibited higher risk taking and innovations, initiated more influence attempts, and employed a greater variety of influence tactics than did non-champions. Regression analysis of a model of champion emergence that related personality characteristics, transformational leader behaviours and influence tactics revealed that champions were significantly higher than non-champions on all paths in the model.

In view of the high degree of technological obsolescence in high-technology organisations, successful management of technological change is an important challenge to a technical leader. Beatty and Lee (1992) used the data from the empirical case studies of the implementation of computer-aided design and manufacturing (CAD-CAM) systems in UK and Canadian companies to indicate that a transformational approach to leadership that combines pathfinding with people problem-solving skills to introduce technological changes is likely to be more effective in overcoming barriers to change than a transactional leadership approach that concentrates on technical problem solving to the neglect of people and organisational issues.

\section{RESEARCH ON IT PROJECT LEADERSHIP}

The author is currently engaged in research on testing the suitability of Transformational Leadership model in Australian IT environment. The research examines the nature of project leadership in an Information Technology set-up. It is aimed at improving the quality of Australian IT project management by focusing on project leadership and other critical success factors. 


\subsection{Sample Design}

The target population is IT companies and IT divisions of major companies in Australia which are engaged in software development activity in a project team environment. The list of organisations which have been invited to participate in the survey is derived from a listing of top 50 software companies (Kennedy, 1996), selected listing of top 100 IT using organisations (Conners, 1995), and selected member organisations of Australian Information Industry Association (AIIA). The survey is actively supported by the Australian Computer Society (ACS), the Australian Institute of Management (AIM) and the AIIA. Nearly 160 organisations were invited to participate in the survey and the response is encouraging $(30 \%)$.

As per the research design, a senior manager of the respondent company, to whom the IT Project Managers report, will select two recent IT projects in his/her company to participate in the survey: one which is more successful in his/her opinion (in terms of technical quality, cost performance, deadlines, customer satisfaction, and overall project performance) and another which is less successful. Both these projects will be at least half way through their duration (life cycle).

The sampling frame consists of the IT project managers and their subordinates. The project manager will indicate his/her leadership behaviour and its perceived effectiveness. The project team members will also separately indicate the nature of the leadership behaviour of their Project Manager and their satisfaction with and the perceived effectiveness of the leadership style.

\subsection{Research Instruments}

The Multi-factor Leadership Questionnaire (MLQ) (Bass and Avolio, 1991) is used to examine leadership in this research. The questionnaire comprises sixty nine items that identify and measure key leadership behaviours. It assesses four transformational leadership factors (charisma, idealised influence, intellectual stimulation and individualised consideration), two transactional leadership factors (contingent reward and management-by-exception), and three outcome factors (satisfaction with the leader, individual and group effectiveness, and extra effort by followers). Twelve additional questions have been added to the MLQ to specifically assess the leadership behaviours of IT managers and are derived from the meta analysis of the existing literature on technical leadership.

The respondents completing the MLQ are asked to judge how often their leader displays each of the 75 items of behaviour, using the following scales: 5 , frequently if not always; 4 , fairly often; 3 , sometimes; 2 , once in awhile; 1 , not at all. The research involving the MLQ has indicated the following Cronbach's coefficient alphas for each leadership factor: Charisma, 0.90, Inspiration, 0.84, Intellectual Stimulation, 0.88, Individualised Consideration, 0.85, Contingent Reward, 0.87, and Management- by- Exception, 0.79 (Bass and Avolio, 1989).

Leadership effectiveness is measured in two ways: one, by subordinate satisfaction ratings and two, by the project performance data provided by the senior manager of the participating organisations. By measuring performance separately from leadership ratings, the common methods bias will be eliminated. 
Apart from leadership, the study also examines other contingency factors which are critical to the success of IT projects. The Project Implementation Profile (PIP) (Slevin \& Pinto, 1986) is used to examine the contingency factors. The PIP identifies ten factors which are critical to the successful project implementation out of which three factors have been further identified as more critical than others in the Execution phase of project life cycle in R\&D projects (including computer software and hardware development) (Pinto \& Slevin, 1989). These factors are Project Mission, Top Management Support and Technical Tasks. The survey respondents will evaluate these factors with reference to their projects.

\subsection{Data Analysis}

A principal components factor analysis with varimax rotation will indicate the correlation between the scales of leadership behaviour and throw light on whether the constructs are distinct or overlapping. LISREL 7 will be used to calculate the true score correlations between the sub-scales of the MLQ and the additional sub-scales on technical leadership to test the overlap between the two. Exploratory and confirmatory factor analysis of the sub-scales will show whether these measures assess a unitary construct of leadership (Carless, 1995). T tests will be conducted to analyse the leadership ratings by subordinates and also the project performance data to see whether transformational leadership behaviours differentiate between effective and ineffective leaders and which of the sub-scales are better discriminators than others.

\subsection{Time Frame for Research}

The research began in March, 1995. The survey questionnaires were distributed between November '95 to February ' 96 . The preliminary results of the survey are expected by July, 1996 and the final results by the end of 1996.

\section{REFERENCES}

Bass, B. M. \& Avolio, B. J. (1989; 1991) Transformational leadership development : manual for the multi-factor leadership questionnaire. Consulting Psychologists Press, California.

Bass, B.M. (1985). Leadership and performance beyond expectations. Free Press, New York.

Beatty, C. and Lee, G. (1992) Leadership among middle managers - an exploration in the context of technological change. Human Relations. 45 (9), 957-989.

Bradford, D. L. and Cohen, H. R. (1984) Managing for excellence. John Weley and Sons, New York.

Carless, S.A. (1995). Transformational leadership and teams: an examination of the Bass and Kouzes-Posner models. Unpublished doctoral dissertation, University of Melbourne.

Cash,C. and Fox, R. (1992). Elements of successful project management. Journal of Systems Management. September, 1992. 10-12.

Conners, E. (1995). MIS 100. Strategic Publishing Group, Sydney. 
Davis, K. (1981). Human behaviour at work. McGraw-Hill, New York.

Howell, J. M. and Higgins, L. A. (1990). Champions of technological innovation. Administrative Science Quarterly, 35 (2), 317-341.

Huey, J. (1994) The new post - heroic leadership. Fortune, 129 (4), 42-50.

Keller, R.T. (1992). Transformational leadership and the performance of research and development project groups. Journal of Management, 18(3), 481-501.

Kennedy, L. (Ed.) (1996). The Software 50. Summer, 1996. IDG Communications, St. Leonards.

Mann, L. (Ed.) (1994). Developing Leaders in R\&D. Business/Higher Education Round Table, Melbourne.

Power, K. (1995). Making the move to management. Computer World. December 1, 1995. 44-45.

Pinto, J.K. and Slevin, D.P. (1989) Critical success factors in R\&D projects. Research Technology Management, January-February 1989, 31-35.

Rosenbaum, B. L. (1991) Leading today's technical professional. Training and development, $45(10), 55-66$.

Schapper, M. et all. (1992). Promoting Partnerships. Taskforce Report No.2. Business/Higher Education Round Table, Melbourne.

Slevin, D.P. and Pinto, J.K. (1986). The project implementation profile: New tool for project managers. Project Management Journal. September 1986. 57-70.

Tichy, N. and Devanna, F. (1986) Transformational leadership. Wiley, New York.

Weinberg, G. M. (1986) Becoming a technical leader. Dorset House, New York. 